\title{
The Effect of Water on the 410-km Discontinuity: An Experimental Study
}

Joseph R. Smyth

Department of Geological Sciences, University of Colorado, Boulder, CO 80309 USA.

Daniel J. Frost,

Bayersiches Geoinstitut, Universität Bayreuth, Bayreuth, D94550 Germany.

\begin{abstract}
In order to evaluate the effect of $\mathrm{H}$ on the pressure and transition interval of the olivine-wadsleyite transformation, synthesis experiments were carried out in hydrous and anhydrous peridotite compositions at $1400^{\circ} \mathrm{C}$. Under hydrous, near-saturated conditions, the pressure of the transition is $1.0 \pm 0.5 \mathrm{GPa}$ lower than under anhydrous conditions. In addition, the two-phase interval appears to broaden from about $0.4 \mathrm{GPa}(12 \mathrm{~km})$ in the anhydrous system to as much as $1.3 \mathrm{GPa}(40 \mathrm{~km})$ in the hydrous system. Under hydrous conditions the spatial distribution of olivine and wadsleyite appears to be controlled by $\mathrm{H}$ diffusion. Extrapolating previously measured diffusion coefficients for $\mathrm{H}$ in olivine and in liquids, it appears that $\mathrm{H}$ diffusion driven by gravitational equilibration may serve to narrow the transition interval between olivine and wadsleyite.
\end{abstract}

\section{Introduction}

The seismic discontinuities at depths of 410 and 660 kilometers, which bound the Transition Zone, are generally thought to be due to phase changes in an olivine-dominated mantle composition. The discontinuity at 410 kilometers corresponds to the olivine-wadsleyite transition with an increase in both density and S-wave velocity of about $5 \%$ (Dziewonski and Anderson, 1981). In the dry peridotite system the olivine-wadsleyite transition is observed experimentally at 13.5 to $14 \mathrm{GPa}$ at about $1600{ }^{\circ} \mathrm{C}$ with a transition interval of at least $0.5 \mathrm{GPa}(\sim 15 \mathrm{~km})$ (Zhang and Herzberg, 1994). Based on thermochemical measurements, Akaogi et al (1989) suggest an interval of $18 \mathrm{~km}$. Seismically, the discontinuity is seen as a very abrupt rise in velocity. Several authors have reported discontinuity thicknesses of four $\mathrm{km}$ or less (Benz and Vidale, 1993, Yamazaki and Hirahara, 1994, Neele, 1996).

Based on electrostatic bond strength calculations, Smyth (1987) suggested that wadsleyite has the potential to hydrate by protonation of its non-silicate oxygen (O1). If this site were fully protonated, the structure might contain as much as 3.3 weight percent $\mathrm{H}_{2} \mathrm{O}$ (Smyth 1994). Gasparik (1993), Inoue (1994), and Kohlstedt et al (1996) observed 3.1 weight percent or more $\mathrm{H}_{2} \mathrm{O}$ in wadsleyite under near watersaturated conditions. This is a geologically significant amount of hydrogen. If saturated, a transition zone containing 70 modal percent wadsleyite could contain four times the amount of water in the hydrosphere and be the largest reservoir of $\mathrm{H}$ in the planet (Inoue et al., 1995).

Kudoh et al. (1996) and Smyth et al. (1997) reported the crystal structure of hydrous wadsleyites and observed cation vacancies in both the Mg and Si sites. Smyth et al. (1997) and Kudoh and Inoue (1999) observed that hydrous wadsleyite may be metrically monoclinic $(I 2 / \mathrm{m})$ instead of the nominally orthorhombic (Imma) structure, but that there is complete crystalline solution between the anhydrous and hydrous varieties. Recently, we have observed that the deviation from orthorhombic symmetry appears to vary with trivalent cation content. Also, the incorporation of $\mathrm{H}$ into this structure has a relatively small effect on the unit cell volume so that the hydrous wadsleyite is still about five percent denser than olivine, which can incorporate only up to about 0.2 weight percent $\mathrm{H}_{2} \mathrm{O}$.

Smyth and Kawamoto (1997) reported an additional variation of the wadsleyite structure similar to spinelloid IV (Horioka et al., 1982), which may be optically indistinguishable from wadsleyite. This structure is intermediate in density and pressure stability between wadsleyite and ringwoodite, but also may require significant amounts of $\mathrm{H}$ and trivalent cations for stabilization. Most model mantle compositions have sufficient $\mathrm{Al}$ for this phase to be a possible constituent of the Transition Zone, and its presence is another possible explanation for the splitting of the discontinuity at $520-\mathrm{km}$ recently reported by Deuss and Woodhouse (2001).

Wood (1995) explored some of the potential thermodynamic consequences of a hydrous Transition Zone. $\mathrm{He}$ reasoned that the presence of $\mathrm{H}$ in the Transition Zone, being more soluble in wadsleyite than olivine must expand the stability field of wadsleyite to lower pressures through configurational entropy of disorder. He then calculated, based on an assumed model for the incorporation of $\mathrm{H}$ into olivine and wadsleyite, that the presence of $500 \mathrm{ppm} \mathrm{H}$ would necessarily expand the transitional $\alpha+\beta$ loop interval from a minimum of about $7 \mathrm{~km}$ for a dry system to at least $22 \mathrm{~km}$. He went on to assert that the observed sharpness of the $410-\mathrm{km}$ discontinuity would be inconsistent with $\mathrm{H}_{2} \mathrm{O}$ contents greater than about $200 \mathrm{ppm}$. Hellfrich and Wood (1996) estimated that the effect of a 10-km transition interval might appear seismically as a $5-\mathrm{km}$ linear velocity gradient. They also concluded in their analysis that the reflectivity of the $410-\mathrm{km}$ discontinuity is much more sensitive to varying $\mathrm{H}_{2} \mathrm{O}$ concentration than to temperature. However, most estimates of the width of the transition interval for the dry system range from 15 to $18 \mathrm{~km}$ based on experimental studies. It therefore appears that the observed transition interval is too narrow for the dry system and would be much too narrow for a hydrous system, unless some other phenomenon is controlling the width.

In order to experimentally test the hypothesis of Wood (1995) that the presence of $\mathrm{H}_{2} \mathrm{O}$ in the Transition Zone 
would extend the stability of wadsleyite to lower pressures and broaden the two-phase region, we have conducted a series of synthesis experiments in the peridotite and olivine systems. We conducted a series of three preliminary synthesis experiments in a hydrous olivine system and a further series of three experiments each in hydrous and anhydrous peridotite systems. By measuring the compositions of the coexisting olivine and wadsleyite by the electron microprobe, we can obtain an estimate of the difference in the width of the transition between hydrous and anhydrous conditions. We also hoped to observe a significant pressure difference for the transition between the wet and dry conditions. We may also be able to observe additional phenomena that might affect the width of the transition interval.

\section{Experimental}

Three preliminary experiments were conducted in a hydrous olivine system with very low trivalent cation content. Starting material (Table 1) was formulated from powdered natural $\mathrm{Fo}_{90}$ olivine, brucite, quartz, and wüstite to achieve a composition of $\mathrm{Fo}_{92}$ plus three weight percent $\mathrm{H}_{2} \mathrm{O}$ with a slight excess of silica. Three principal experiments were conducted in a hydrous peridotite system with a slight excess of silica and alumina. The starting material was formulated from powdered natural $\mathrm{Fo}_{90}$ olivine, plus synthetic brucite, quartz, pyrope and wüstite to achieve a composition of $\mathrm{Fo}_{88}$ plus three weight percent $\mathrm{H}_{2} \mathrm{O}$ with a sufficient excess of silica and alumina to give approximately five normative percent each of pyroxene and pyropealmandine garnet. Finally, three experiments were conducted in an anhydrous peridotite system. The starting material was formulated from powdered natural $\mathrm{Fo}_{90}$ olivine, plus synthetic quartz, pyrope and wüstite to achieve a composition of $\mathrm{Fo}_{90}$ with a sufficient excess of silica and alumina to give approximately five normative percent each of pyroxene and pyrope-almandine garnet.

The charges were sealed in welded $\mathrm{Pt}$ capsules $2 \mathrm{~mm}$ in diameter and $3.5 \mathrm{~mm}$ in length. $\mathrm{A}_{\mathrm{Cr}_{2} \mathrm{O}_{3} \text {-doped } \mathrm{MgO}}$ multianvil octahedron of $18 \mathrm{~mm}$ edge-length was employed with a stepped lanthanum chromate heater. The capsule was placed into the assembly inside an $\mathrm{MgO}$ sleeve. A 5000-ton press at the Bayerisches Geoinstitut was used to compress the octahedra using 52-mm edge-length WC anvils with 11$\mathrm{mm}$ corner truncations. The heating time for each experiment was nominally 5 hours. The temperature was monitored and controlled to within $1{ }^{\circ} \mathrm{C}$ during the experiments using a $\mathrm{W} 3 \% \mathrm{Re} / \mathrm{W} 25 \% \mathrm{Re}$ thermocouple that was inserted axially into the assembly. The $18 / 11$ multi-anvil assembly was calibrated using the coesite to stishovite transition at $1000^{\circ} \mathrm{C}$ (Zhang et al., 1996), the $\mathrm{Mg}_{2} \mathrm{SiO}_{4}$ forsterite to wadsleyite transition at $1200^{\circ} \mathrm{C}$ (Morishima et al., 1994) and the $\mathrm{Mg}_{2} \mathrm{SiO}_{4}$ wadsleyite to ringwoodite transition at $1200^{\circ} \mathrm{C}$ (Suzuki et al., 2000). The Fe-Mg partitioning between phases in the anhydrous peridotite experiments was compared with the results of Katsura and Ito (1989) to provide an additional constraint on the reproducibility of the pressure measurements. The accuracy in the absolute pressure measurement is around $1 \mathrm{GPa}$ when the uncertainties in the calibrant pressure estimates are considered but the reproducibility of the experimental pressure is within $0.5 \mathrm{GPa}$.
The possible presence of wadsleyite II (Smyth and Kawamoto, 1997) or of monoclinic wadsleyite (Smyth et al., 1997), necessitated characterization of run products by single crystal X-ray diffraction if possible. Capsules were opened and polished for chemical analysis by electron microprobe. In addition, crystals were selected for singlecrystal X-ray diffraction study. Experimental compositions, run-conditions, and products are listed in Table 1. Determination of $\mathrm{H}$ contents run products is beyond the scope of the current report. The most reliable methods for $\mathrm{H}$ content determination for olivine is by ${ }^{15} \mathrm{~N}$ nuclear reaction analysis or by polarized IR spectroscopy on oriented, faceted single crystals (Bell et al, 2002). Reliable calibration of the IR spectra of wadsleyite for H-content is not yet available, but is the subject of ongoing study.

\section{Discussion}

The compositions of co-existing olivine and wadsleyites are shown in Figure 1. In the anhydrous system, the width of the two-phase region at $1400^{\circ} \mathrm{C}$ appears to be about $0.4 \mathrm{GPa}$ or about $12 \mathrm{~km}$ depth interval. This is consistent with previous experimental and thermochemical studies, although at the high end of the 4 to $12 \mathrm{~km}$ advocated by Hellfrich and Wood (1996). In the hydrous system, the two phase regions widens to about $1.3 \mathrm{GPa}$ or about $40 \mathrm{~km}$, and the pressure of the transition is $1.0 \pm 0.5 \mathrm{GPa}$ lower than in the anhydrous system. The estimate of the width of the two-phase region is based on the chemical analyses, and not on the pressure calibration. The results of our synthesis experiments are thus consistent with the prediction of Wood (1995) that the presence of $\mathrm{H}_{2} \mathrm{O}$ extends the stability of wadsleyite to 0.6 to 1.0 GPa lower pressure and would necessarily broaden the two-phase loop to as much as $40 \mathrm{~km}$. So, both the observed $40 \mathrm{~km}$ interval in the hydrous system and $12 \mathrm{~km}$ interval in the anhydrous system are still too broad to be consistent with the seismic observations.

It should be noted that in the hydrous system, the largest difference between the wadsleyite and olivine compositions is not the $\mathrm{Fe}$ content, but the $\mathrm{H}$ content, with the $\mathrm{H}$ content of wadsleyite being about ten times that of olivine. Moreover, in all of the experimental hydrous runs containing both olivine and wadsleyite, there appears a sharp boundary between the regions of olivine and wadsleyite. The texture of the hydrous runs may be responding to small thermal gradients and does not appear to be a simple chemical equilibrium, but rather a diffusion-controlled boundary. This is in sharp contrast to the anhydrous runs in which the wadsleyite grains appear evenly distributed throughout the capsule. Hydrogen is known to diffuse very rapidly in these materials. This raises the possibility that diffusion of $\mathrm{H}$ might control the texture and may affect the sharpness of the boundary in the natural system.

Solid-state diffusion of $\mathrm{H}$ is rapid in single-crystal olivine (Mackwell and Kohlstedt, 1990). Charge compensation is provided by a divalent cation vacancy, and vacancy diffusion is also very rapid (Mackwell et al., 1988). Hydrous wadsleyite is still about 5\% more dense than anhydrous olivine (e.g. Smyth et al., 2000). This is comparable to the relative density difference between water and ice. In a hypothetical two-phase region consisting of olivine and wadsleyite plus lesser amounts of garnet and clinopyroxene extending over a depth of $20 \mathrm{~km}$ in a hydrous 
system, gravitational equilibrium can be approached by diffusion of $\mathrm{H}$ without the much slower movement of iron. This gravity-driven diffusion may enrich the lower parts of the two-phase region in wadsleyite and the upper part in olivine, thus sharpening the boundary. This plausible mechanism may sharpen the apparent boundary to four kilometers or less as indicated in some seismic studies (Benz and Vidale 1993, Vidale et al., 1995). Because diffusion of $\mathrm{H}$ is considerably more rapid than convection over short distances, it might cause the transition zone to serve as a trap for $\mathrm{H}$ in the Earth.

It is possible to estimate some of the parameters that might constrain such an effect. First, the velocity of diffusion will constrain $\mathrm{H}$ distribution equilibrium. Mackwell and Kohlstedt (1990) measured diffusion coefficients for $\mathrm{H}$ in solid-state, single-crystal olivine at between $10^{-9}$ and $10^{-10} \mathrm{~m}^{2} \mathrm{~s}^{-1}$ at 800 and $1000^{\circ} \mathrm{C}$. These would extrapolate to about $10^{-8}$ to $10^{-9}$ at $1400^{\circ} \mathrm{C}$. These values are large enough to achieve $\mathrm{H}$ distribution equilibrium in grains that are millimeters in diameter in a matter of minutes or, over a $5 \mathrm{~cm}$ annual convection movement in less than a day. Because the equilibration time scales with the square of distance, $\mathrm{H}$ diffusion could not stay ahead of convection in an actively convecting region of the mantle. If extrapolated, these values indicate equilibration over $10 \mathrm{~km}$ in about 300 million years. These diffusion coefficients values were obtained at pressures of $300 \mathrm{MPa}$ where olivine has as relatively low $\mathrm{H}$ content $(\sim 200 \mathrm{ppm}$ $\mathrm{H}_{2} \mathrm{O}$ by weight). At pressures above $10 \mathrm{GPa}$, Kohlstedt et al. (1996) observed $\mathrm{H}$ contents an order of magnitude higher ( $\sim 2000$ ppm $\mathrm{H}_{2} \mathrm{O}$ by weight). If diffusion coefficients increase with increasing concentration of $\mathrm{H}$ defects, diffusion would be even more rapid due to the higher $\mathrm{H}$ contents. Also, there are no solid-state diffusion data for $\mathrm{H}$ in wadsleyite, but the maximum $\mathrm{H}_{2} \mathrm{O}$ contents are an order of magnitude higher than the high-pressure olivine ( 33,000ppm by weight), and Chakraborty et al (1999) report cation diffusions rates one to two orders of magnitude faster in wadsleyite than in olivine.

Grain boundaries in mantle rocks that have undergone phase changes tend to be complex polyphase assemblages that can constitute up to several percent of the rock (McCormick et al., 1994). In such rocks, movement of $\mathrm{H}$ may be controlled by diffusion in grain boundaries, so the single-crystal values cited above can be regarded as lower bounds. Grain boundary diffusion of $\mathrm{H}$ is likely to approach that of mafic magmas. Chekhmir et al (1985) suggest a diffusion coefficient of $10^{-6} \mathrm{~m}^{2} \mathrm{~s}^{-1}$ for $\mathrm{H}$ in molten basalt, which is two to three orders of magnitude larger than in the crystals, and comparable to the diffusion of heat (Watson, 1991). It is difficult to estimate the contribution of grain boundaries, but it will vary with grain size and may constitute one percent of the cross-sectional area in some mantle rocks. Whole-rock diffusion coefficients for $\mathrm{H}$ in peridotite at $1400^{\circ} \mathrm{C}$ may then be one to two orders of magnitude larger than for single-crystals, or sufficient to allow equilibration over a $10 \mathrm{~km}$ interval in a few tens of millions of years. Some additional experimental data on whole-rock and single-crystal diffusion of $\mathrm{H}$ under pressure and temperature conditions relevant to the $410-\mathrm{km}$ discontinuity may help to further constrain this phenomenon.

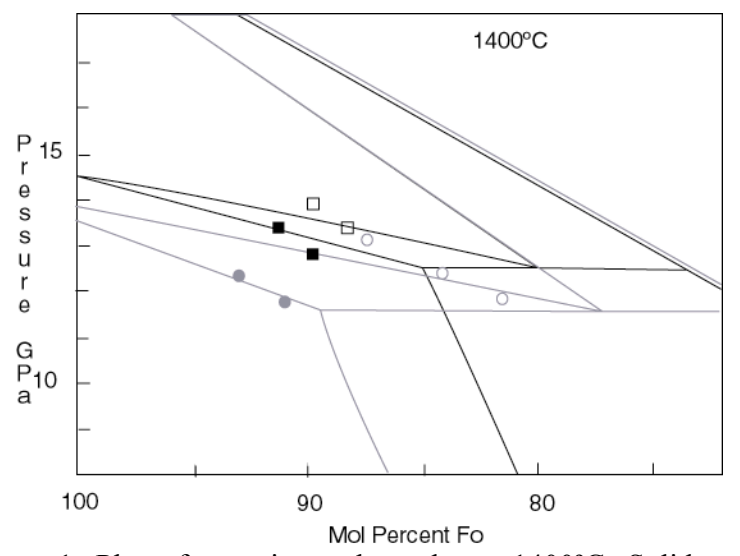

Figure 1. Plot of experimental results at $1400^{\circ} \mathrm{C}$. Solid symbols represent olivine and open symbols wadsleyite. Gray symbols and boundaries represent the hydrous experiments and black the anhydrous.

Second, it is possible to estimate the driving force for establishment of gravitational equilibrium. If we take a hypothetical one-by-one meter volume across a $20-\mathrm{km}$ twophase region, and re-establish gravitational equilibrium by moving all of the wadsleyite to the bottom and olivine to the top we release an energy, E, given by

$$
\mathrm{E}=\mathrm{V} \Delta \rho g h \text {, }
$$

where $\mathrm{V}$ is the volume which would be $2500 \mathrm{~m}^{3}$ for wadsleyite in the upper half of the volume. $\Delta \rho$ is the density difference between wadsleyite and olivine taken as $5 \%$ or $150 \mathrm{~kg} / \mathrm{m}^{3} ; g$ is the acceleration of gravity, $9.8 \mathrm{~ms}^{-2}$; and $h$ is distance the volume moves to re-establish equilibrium. This is approximately $6 \mathrm{~km}$ for the $20-\mathrm{km}$ column (center of mass for the upper volume to the center of mass of the lower volume). This gives about $2.2 \times 10^{10} \mathrm{j}$ for the volume undergoing reaction, or about $2.5 \mathrm{kj} / \mathrm{kg}$, enough to raise the temperature of the volume by approximately one degree Celcius. This neglects smaller PdV term and assumes balance in the heats of reaction, but it may provide a sufficient amount of energy to act as a driving force for the establishment of gravitational equilibrium in regions where there is little vertical movement of material across the boundary. Comprehensive computer modeling will be required to further constrain the possibility of this phenomenon, but is beyond the scope of the current study.

In summary, we have carried out a series of experimental synthesis runs in order to evaluate the effect of $\mathrm{H}_{2} \mathrm{O}$ on the position and sharpness of the $410-\mathrm{km}$ discontinuity. Run products have been carefully characterized by electron microprobe and single-crystal X-ray diffraction. Under nearsaturated conditions, the pressure of the transition is $1.0 \pm$ $0.5 \mathrm{GPa}$ lower than under anhydrous conditions. In addition, the two-phase interval appears to broaden from about 0.4 $\mathrm{GPa}(12 \mathrm{~km})$ in the anhydrous system to as much as $1.3 \mathrm{GPa}$ $(40 \mathrm{~km})$ in the water-saturated system. Chemical analysis indicates that the largest chemical difference between olivine and wadsleyite is the hydrogen content. Textures in the hydrous experiments suggest that $\mathrm{H}$ diffusion controls the spatial distribution of the olivine and wadsleyite phases. Evaluating this possibility, diffusion coefficients for $\mathrm{H}$ in solid-state single-crystal olivine appear to be large enough to allow $\mathrm{H}$ distribution equilibration over a $20-\mathrm{km}$ interval in a few hundred million years, or less if grain boundary effects 
are considered. In any case, $\mathrm{H}$ diffusion cannot outpace convection in regions of significant convective flow across the boundary. However such regions are confined to subduction zones and spreading centers, and seismic observations of the narrow boundary regions were not made in these regions.

If this diffusion mechanism does indeed function to control the distribution of olivine and wadsleyite near the $410 \mathrm{~km}$ discontinuity, then the presence of $\mathrm{H}$ may cause the transition at $410 \mathrm{~km}$ to be sharper and shallower and velocities in the region slower than under anhydrous conditions. Under cool, anhydrous conditions the transition would be shallower and velocities faster than under hot anhydrous conditions. Further work will be required to quantify the effect of $\mathrm{H}$ on elastic properties, but it appears that the effect of $\mathrm{H}$ on the depth of the transition and on velocities will be larger than possible variation in temperature.

\section{Acknowledgments}

This work was supported by NSF grant EAR 0087279 and by the Bayerisches Geoinstitut visitors program. The authors thank Ray Fletcher, Peter Molnar, Hersh Gilbert, and Steven Jacobsen for helpful discussions.

\section{References}

Akaogi, M., E. Ito, and A. Navrotsky, Olivine-modified spinel transitions in the system $\mathrm{Mg}_{2} \mathrm{SiO}_{4}-\mathrm{Fe}_{2} \mathrm{SiO}_{4}$ : calorimetric measurements, thermochemical calculation, and geophysical application. J. Geophys Res. 94, 15,671- 15,685, 1989.

Bell, D.R., G.R. Rossman, J. Maldener, D. Endisch, and F. Rauch, Hydroxide in olivine: A quantitative determination of the absolute amount and calibration of the IR spectrum. J. Geophys Res. 107, (in press), 2002.

Benz, H. M., and J. E. Vidale, Sharpness of upper mantle discontinuities determined from high-frequency reflections. Nature 365, 147-150, 1993.

Chakraborty, S., R. Knoche, H. Schulze, D.C. Rubie, D. Dobson, N.L. Ross and R. Angel, Enhancement of cation diffusion rates across the 410-kilometer discontinuity., Science 283, 362-365.

Chekhmir, A.S., E. S. Persikov, M. B. Epel'baum, and P. G. Bukhtiyarov, Hydrogen transport through a model magma. Geokhimiya 5, 594-598, 1985.

Deuss, A., and J. Woodhouse, Seismic observations of splitting of the mid-transition zone discontinuity in Earth's mantle. Science 294, 354-357, 2001.

Dziewonski A. and D. L. Anderson, Preliminary reference Earth model. Phys. Earth. Planet. Int. 25, 297-356, 1981.

Gasparik, T. The role of volatiles in the transition zone. J. Geophys. Res 98, 4287-4299, 1993.

Gudfinnsson, G.H., and B. J. Wood, The effect of trace elements on the olivine-wadsleyite transformation. Am. Mineral., 83, 1037 1044, 1998.

Hellfrich, G.R. and B. J. Wood, 410-km discontinuity sharpness and the form of the olivine $\alpha-\beta$ phase diagram: resolution of apparent seismic contradictions. Geophys J. Int. 126, F7-F12, 1996.

Horioka, K., K. Takahashi, N. Morimoto, H. Horiuchi, M. Akaogi and S. Akimoto, Structure of nickel aluminosilicate (Phase IV): A high-pressure phase related to spinel. Acta Cryst., B37, 635638, 1981.

Inoue, T., H. Yurimoto, and Y. Kudoh, Hydrous modified spinel, Mg1.75SiH0.5O4: A new water reservoir in the mantle transition region. Gephys. Res. Lett. 22, 117-120, 1995.
Katsura, T., and E. Ito, The system $\mathrm{Mg}_{2} \mathrm{SiO}_{4}-\mathrm{Fe}_{2} \mathrm{SiO}_{4}$ at high pressures and temperatures: Precise determination of stabilities of olivine, modified spinel, and spinel. J. Geophys. Res. 94, 15,663-15,670, 1989.

Kohlstedt, D.L., H. Keppler, and D. C. Rubie, The solubility of water in $\alpha, \beta$ and $\gamma$ phases of $(\mathrm{Mg}, \mathrm{Fe})_{2} \mathrm{SiO}_{4}$. Contrib. Mineral. Petrol., 123, 345-357, 1996.

Kudoh, Y., T. Innoue and H. Arashi, Structure and crystal chemistry of hydrous wadsleyite, $\mathrm{Mg}_{1.75} \mathrm{H}_{0.5} \mathrm{SiO}_{4}$ : possible hydrous magnesium silicate in the mantle transition zone. Phys. Chem. Minerals 23, 461-469, 1996

Kudoh, Y., and $\mathrm{T}$. Inoue, Mg-vacant structural modules and dilution of symmetry of hydrous wadsleyite, $\beta-\mathrm{Mg}_{2-\mathrm{x}} \mathrm{SiH}_{2 \mathrm{x}} \mathrm{O}_{4}$ with $0.00<\mathrm{x}<0.25$. Phys. Chem. Minerals 26, 382-388, 1999.

Mackwell, S. J. and D. L. Kohlstedt, Diffusion of H in olivine: Implications for water in the mantle. J. Geophys. Res. 95, 50795088, 1990.

Mackwell, S.J., D. Dimos, and D. L. Kohlstedt, Transient creep of olivine: point defect relaxation time. Philos. Mag. 57, 779-789, 1988.

McCormick, T.C., J.R. Smyth and F.A. Caporuscio (1994) Chemical systematics of secondary phases in mantle eclogites. Kimberlites, Related Rocks and Mantle Xenoliths (H.O.A. Meyer and O.H. Leonardos eds.) CPRM Brasilia, 405-419.

Morishima H., T. Kato, M. Suto, E. Ohtani, S. Urakawa, W. Utsumi, O. Shimomura, and T. Kikegawa, The phase boundary between $\alpha$ and $\beta-\mathrm{Mg}_{2} \mathrm{SiO}_{4}$ determined by in situ X-ray observation. Science 265, 1202-1203, 1994.

Neele, F., Sharp 400-km discontinuity from short-period P reflections. Geophys. Res. Lett. 23, 419-422, 1996.

Smyth, J. R., $\beta-\mathrm{Mg}_{2} \mathrm{SiO}_{4}$ : A potential host for water in the mantle? Am. Mineral. 72, 1051- 1055, 1987.

Smyth, J.R., A crystallographic model for hydrous wadsleyite ( $\beta$ $\left.\mathrm{Mg}_{2} \mathrm{SiO}_{4}\right)$ : an ocean in the Earths interior? Am Mineral. 79, 1021-1024, 1994.

Smyth, J.R., and T. Kawamoto, Wadsleyite II: a new high pressure hydrous phase in the peridotite- $\mathrm{H}_{2} \mathrm{O}$ system. Earth Planet. Sci. Lett. 146, E9-E16, 1997.

Smyth, J. R., T. Kawamoto, S. D. Jacobsen, R. J. Swope, R. L. Hervig, and J. R. Holloway, Crystal structure of monoclinic hydrous wadsleyite $\left[\beta-(\mathrm{Mg}, \mathrm{Fe})_{2} \mathrm{SiO}_{4}\right]$. Am. Mineral., 82, 270275, 1997.

Smyth, J.R., S. D. Jacobsen, and R.M. Hazen, Comparative crystal chemistry of orthosilicate minerals. Rev Mineral. 41, 187-210, 2000.

Suzuki A., E. Ohtani, H. Morishima, T. Kubo, Y. Kanbe, and T. Kondo, In situ determination of the phase boundary between wadsleyite and ringwoodite in $\mathrm{Mg}_{2} \mathrm{SiO}_{4}$. Geophys Res Lett 27 , 803-806, 2000.

Vidale, J.E., X.-Y. Ding, and S. P. Grand, The 410-km-depth discontinuity: A sharpness estimate from near-critical reflections. Geophys. Res. Lett. 22, 2557-2560, 1995.

Watson, E.B., Diffusion in volatile-bearing magmas. Rev. Mineral. 30, 371-411, 1994.

Wood, B.J., The effect of $\mathrm{H}_{2} \mathrm{O}$ on the 410-kilometer seismic discontinuity. Science 268, 74-76, 1995.

Yamazaki, A. and K. Hirahara, The thickness of upper mantle discontinuities as inferred from short-period J-Array data. Geophys. Res. Lett. 21, 1811-1814, 1994.

Zhang, J., and C. T. Herzberg, Melting experiments on anhydrous peridotite KLB-1from 5.6 to 22.5 GPa. J. Geophys Res 99, 17729-17742, 1994.

Zhang, J., B. Li, W. Utsumi and R.C. Liebermann, In Situ X-ray observations of the coesite-stishovite transformation: reversed phase boundary and kinetics Phys. Chem. Minerals 23, 1-10, 1996. 
Table 1. Results of Synthesis Experiments

\begin{tabular}{|c|c|c|c|c|c|c|c|c|c|}
\hline Run & SS0001 & SS0003 & SS0004 & SZ0101 & SZ0102 & SZ0103 & SZ0109 & SZ0110 & SZ0111 \\
\hline Composition* & 1 & 1 & 1 & 2 & 2 & 2 & 3 & 3 & 3 \\
\hline $\mathrm{P}(\mathrm{GPa})$ & 12.0 & 12.0 & 12.0 & 13.2 & 11.8 & 12.5 & 13.2 & 13.9 & 12.5 \\
\hline $\mathrm{T}\left({ }^{\circ} \mathrm{C}\right)$ & 1200 & 1400 & 1600 & 1400 & 1400 & 1400 & 1400 & 1400 & 1400 \\
\hline \multicolumn{10}{|l|}{ Olivine } \\
\hline Fo\# & 97.8 & 92.7 & 92. & & 91.0 & 92.9 & 91.2 & & 92.4 \\
\hline Modal $\%$ & 15 & 100 & 100 & 0 & 90 & 50 & 50 & 0 & 98 \\
\hline \multicolumn{10}{|l|}{ Wadsleyite } \\
\hline Fo\# & 90.8 & & & 87.7 & 84.0 & 84.2 & 88.2 & & 88.2 \\
\hline Modal $\%$ & 85 & 0 & 0 & 100 & 10 & 50 & 50 & 95 & 2 \\
\hline \multicolumn{10}{|l|}{ Garnet } \\
\hline Modal\% & 0 & 0 & 0 & 3 & 5 & 5 & 5 & 5 & 5 \\
\hline \multicolumn{10}{|l|}{ Clinopyroxene } \\
\hline Modal\% & 0 & 0 & 0 & 5 & 5 & 5 & 0 & 0 & 0 \\
\hline
\end{tabular}

*Composition 1. Hydrous olivine: approximately $\mathrm{Fo}_{92}$ olivine plus $3 \% \mathrm{H}_{2} \mathrm{O}$.

*Composition 2. Hydrous peridotite: approximately $\mathrm{Fo}_{89}$ olivine plus $3 \% \mathrm{H}_{2} \mathrm{O}$ with minor garnet and excess silica.

*Composition 3. Anhydrous peridotite: approximately $\mathrm{Fo}_{92}$ olivine with minor garnet and excess silica. 